\title{
CENTRALLY MEDIATED CARDIOVASCULAR RESPONSES TO INTRACISTERNAL INJECTIONS OF SYMPATHOMIMETIC AMINES IN ANESTHETIZED RATS
}

\author{
Hikaru OZAWA and Toshio UEMATSU \\ Department of Pharmacology, Pharmaceutical Institute, \\ Tohoku University, Aobayama, Sendai 980, Japan
}

Accepted October 2, 1975

\begin{abstract}
The cardiovascular effects resulting from intracisternal (i.c.) injections of sympathomimetic amines were studied in $\alpha$-chloralose-urethanized rats. Norepinephrine (0.5-5 $\mu$ g i.c.) caused a typical rise in blood pressure with no significant change in heart rate and a fall in blood pressure with a bradycardia, which were completely blocked after treatment with phentolamine (10-50 $\mu \mathrm{g}$ i.c.). L-isoproterenol $(0.05-0.5$ $\mu \mathrm{g}$ i.c.) and trimetoquinol (0.5-3 $\mu \mathrm{g}$ i.c.), a $\beta$-sympathomimetic agent, usually caused a fall in blood pressure with a tachycardia, which was reduced after treatment with propranolol (10-50 $\mu$ g i.c.), but trimetoquinol was inclined to cause a rise in blood pressure with a tachycardia. Epinephrine (5 $\mu$ g i.c.) showed both centrally mediated $\alpha$ - and $\beta$-sympathomimetic effects. Tyramine $(0.5-1 \mathrm{mg}$ i.c.) caused mixed blood pressure responses presumably due to a release of norepinephrine and epinephrine, and these responses were partially blocked after treatment with phentolamine $(100 \mu \mathrm{g}$ i.c.) or propranolol (50 $\mu \mathrm{g}$ i.c.). These observations suggest that both $\alpha$ - and $\beta$ sensitive adrenergic zones may exist on the vasomotor center of the pons and medulla in rats, and both norepinephrine and epinephrine might centrally play a physiological role as the neurotransmitters controlling blood pressure in rats.
\end{abstract}

It is assumed that the vasomotor centers regulating cardiovascular responses are located in the hypothalamus and the medulla oblongata. Since norepinephrine is regarded as one of the possible physiological neurotransmitters controlling the activities of the vasomotor centers, centrally mediated cardiovascular effects of norepinephrine and its related amines directly injected into the lateral cerebral ventricle in dogs $(1,2)$, cats (3-6) and rabbits (7) have been examined. It has been reported that the intraventricular (i. vt.) injection of norepinephrine usually causes a fall in blood pressure with a bradycardia, which is blocked by treatment with i. vt. $\alpha$-adrenergic receptor blocking agents, and on the other hand, i. vt. isoproterenol usually causes a fall in blood pressure with a tachycardia, which is blocked by treatment with i.vt. $\beta$-adrenergic receptor blocking agents, in anesthetized dogs, cats or rabbits. Thus, much evidence for the possible existence of $\alpha$ - and $\beta$-adrenergic receptors in the central nervous system as well as in the peripheral nervous system has been accumulated. Particularly, it has been recently reported that there may exist both $\alpha$-and $\beta$-adrenergic receptors on the vasomotor center in cats (8).

Since there is a paucity in the literature concerning the effects of sympathomimetic agents administered into the cisterna magna in rats, such effects on the central sympathetic tones in anesthetized rats were studied herein by observing blood pressure and heart rate, and in addition, relatively smaller doses of drugs were injected into the limited area in the cisterna 
magna in order to clarify the precise mode of actions of sympathomimetic agents in the pons and medulla.

\section{MATERIALS AND METHODS}

Male Wistar rats weighing $300-400 \mathrm{~g}$ were used. Light ether anesthesia served as induction and a cannula was inserted into the jugular vein in order to inject drugs intravenously. After anesthesia with $\alpha$-chloralose $(80 \mathrm{mg} / \mathrm{kg}$ i.v. $)$-urethane $(500 \mathrm{mg} / \mathrm{kg}$ i.v. $)$ and the cannulation of the trachea, a fine polyethylene cannula $(0.2 \mathrm{~mm}$ in diameter, $10 \mathrm{~cm}$ in length) was inserted into the cisterna magna foramen through the punctured core of the dura at the spinal $C_{1}-C_{2}$ level in order to inject drugs repeatedly. The tip of the inserted cannula was placed on a point $8-10 \mathrm{~mm}$ from the core of the dura toward the pons and medulla so that the drugs would act on the limited area, and then the outside cannula was fixed to the surrounding tissues by using a quick set adhesive (Aron Alpha, Tokyo Kasei).

Systemic blood pressure was recorded from the right common carotid artery via a pressure trasducer (Nihon Kohden, MPU-0.5) on a polygraph (Nihon Kohden, RM-180) or a rectigraph (San-ei Instrument, $8 \mathrm{~S}$ ). Heart rate was recorded by using a pulse rate tachometer (Nihon Kohden, RT-5), or a heartratemeter (San-ei Instrument, 2130) triggered by the pulse of blood pressure.

Drugs used were norepinephrine hydrochloride (Sankyo), epinephrine hydrochloride (Sankyo), 1-isoproterenol hydrochloride (Nikken Kagaku), 1-(3,4,5-trimethoxybenzyl)-6,7dihydroxy-1,2,3,4-tetrahydroisoquinoline hydrochloride (Trimetoquinol, Tanabe), tyramine hydrochloride (Daiichi Kagaku), phentolamine mesylate (Takeda), propranolol hydrochloride (Sumitomo Kagaku), guanethidine sulfate (Takeda) and desmethylimipramine hydrochloride (Geigy-Fujisawa).

Drugs were dissolved in $0.9 \% \mathrm{NaCl}$ (saline), and the solutions $(10 \mu \mathrm{l} / \mathrm{rat})$ were injected intracisternally through the inserted cannula and flushed immediately with saline (10 $\mu \mathrm{l})$. When intravenous injections of the solutions were given, a volume of $0.5 \mathrm{ml} / \mathrm{kg}$ was used. All doses were expressed as $\mu \mathrm{g} / \mathrm{kg}$ or $\mathrm{mg} / \mathrm{kg}$ of salts.

\section{RESULTS}

\section{Norepinephrine}

Norepinephrine $(5 \mu \mathrm{g}$ i.c.) showed variable blood pressure responses such as those illustrated in Fig. 1. These responses consisted of a mild durable fall in blood pressure with a lowering of pulse pressure and a remarkable bradycardia (Fig. 1A), a rise in blood pressure with an enlargement of pulse pressure and a remarkable bradycardia followed by a fall in blood pressure with a lowering pulse pressure and a bradycardia (Fig. 1B and Fig. 1C) and then a rise in blood pressure with an enlargement of pulse pressure and a slight tachycardia (Fig. 1D). In the case of Fig. 1A, 1B or 1C, the blood pressure response was always accompanied by a decrement of respiration rate. Moreover, a considerable time lag was sometimes observed between changes in blood pressure and heart rate caused by i.c. norepinephrine as typically illustrated in Fig. 1C. These blood pressure responses caused by 
i.c. norepinephrine $(5 \mu \mathrm{g})$ had more variable durations, but were usually much longer than those of i.v. norepinephrine $(5 / \mathrm{g})$. In particular, the maximum duration of the hypotension with a bradycardia caused by i.c. norepinephrine $(5 \mu \mathrm{g})$ was over $30 \mathrm{~min}$. Since these blood pressure responses of i.c. norepinephrine may be classified into two typical types such

A

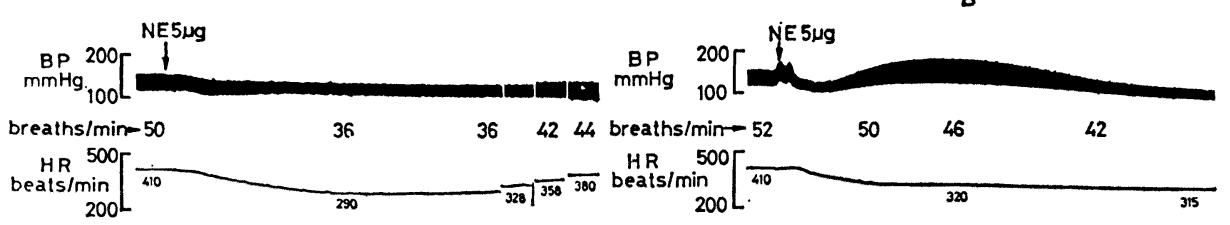

C
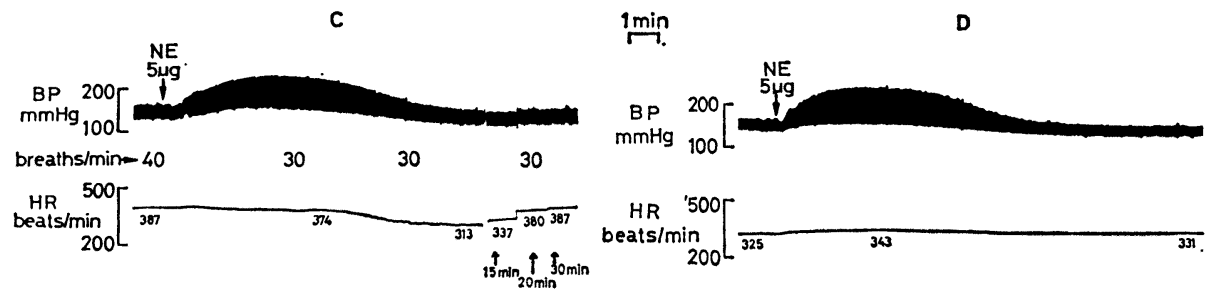

HR
beats/min
200

$15 \min _{20 \min }^{\uparrow} \oint_{0 \mathrm{~min}}$

FIG. 1. Representative blood pressure responses caused by intracisternal (i.c.) injections of norepinephrine (NE) in anesthetized rats.

Each and all charts of A, B, C and D were obtained from four different rats (Chart speed: $10 \mathrm{~mm} / \mathrm{min}$ ).

BP: blood pressure $(\mathrm{mm} \mathrm{Hg}), \mathrm{HR}$ : heart rate (beats $/ \mathrm{min}$ )

Respiration rate is indicated as breaths/min.
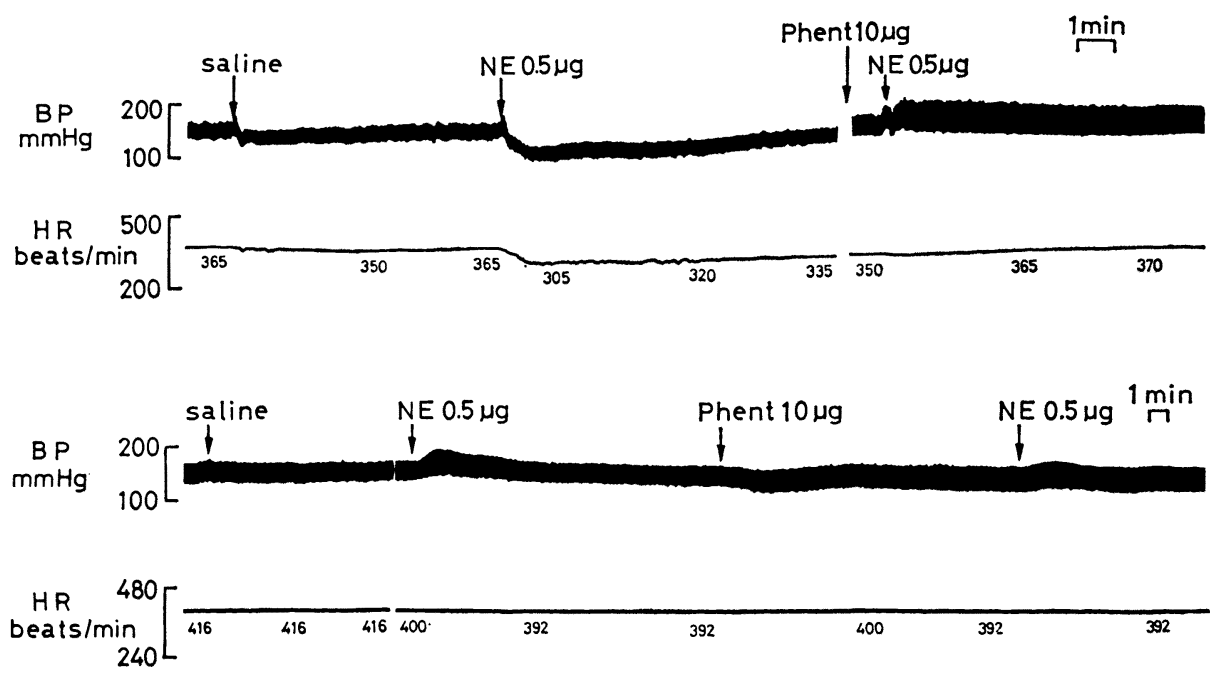

FIG. 2. Typical blood pressure responses caused by intracisternal (i.c.) injections of a smaller dose of norepinephrine (NE) before and after treatment with i.c. phentolamine (Phent) in anesthetized rats.

Upper and lower charts were obtained from two different rats (Upper chart speed: $10 \mathrm{~mm} / \mathrm{min}$, Lower chart speed: $5 \mathrm{~mm} / \mathrm{min}$ ). The second $\mathrm{NE}$ was injected $20 \mathrm{~min}$ after treatment with Phent.

BP: blood pressure $(\mathrm{mm} \mathrm{Hg}), \mathrm{HR}$ : heart rate (beats/min) 


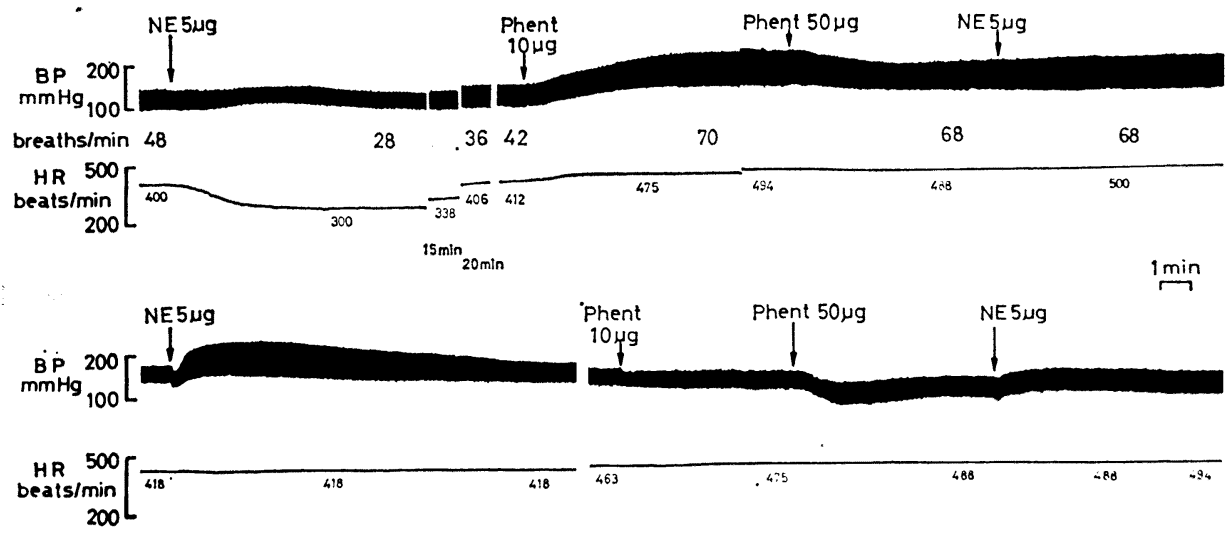

Fig. 3. Typical blood pressure responses caused by intracisternal (i.c.) injections of norepinephrine (NE) before and after treatment with i.c. phentolamine (Phent) in anesthetized rats.

Upper and lower charts were obtained from two different rats (Chart speed: $10 \mathrm{~mm} / \mathrm{min}$ ).

BP: blood pressure (mm $\mathrm{Hg}), \mathrm{HR}$ : heart rate (beats/min)

A

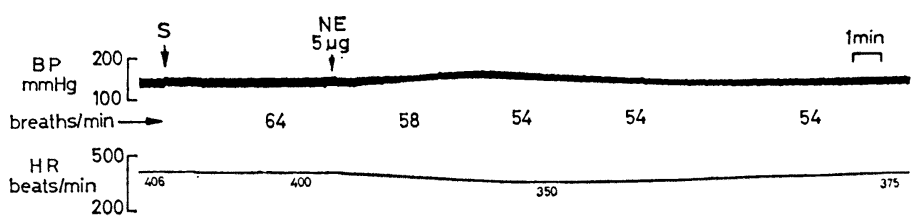

B

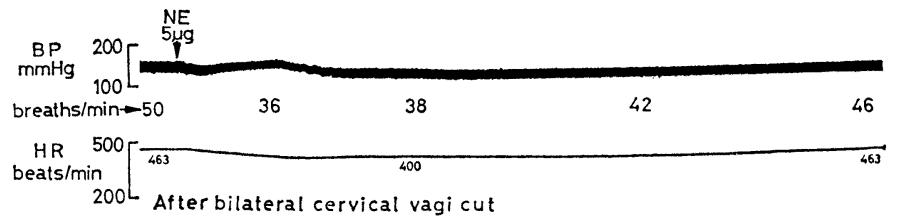

D

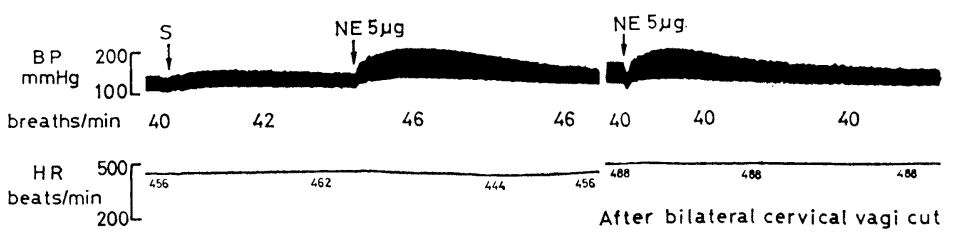

FIG. 4. Typical blood pressure responses in anesthetized rats caused by intracisternal (i.c.) injections of norepinephrine (NE) when the bilateral cervical vagal nerves had been cut. Charts $\mathrm{A}$ and $\mathrm{B}$ or charts $\mathrm{C}$ and $\mathrm{D}$ were obtained from the same rat. Charts $\mathrm{A}$ and $\mathrm{C}$ were control responses, while charts $\mathrm{B}$ and $\mathrm{D}$ were the responses $20 \mathrm{~min}$ after the bilateral cervical vagal nerves had been cut (Chart speed: 10 $\mathrm{mm} / \mathrm{min})$.

BP: blood pressure ( $\mathrm{mm} \mathrm{Hg}$ ), HR: heart rate (beats/min) $\mathrm{S}$ : saline

Respiration rate is indicated as breaths $/ \mathrm{min}$. 


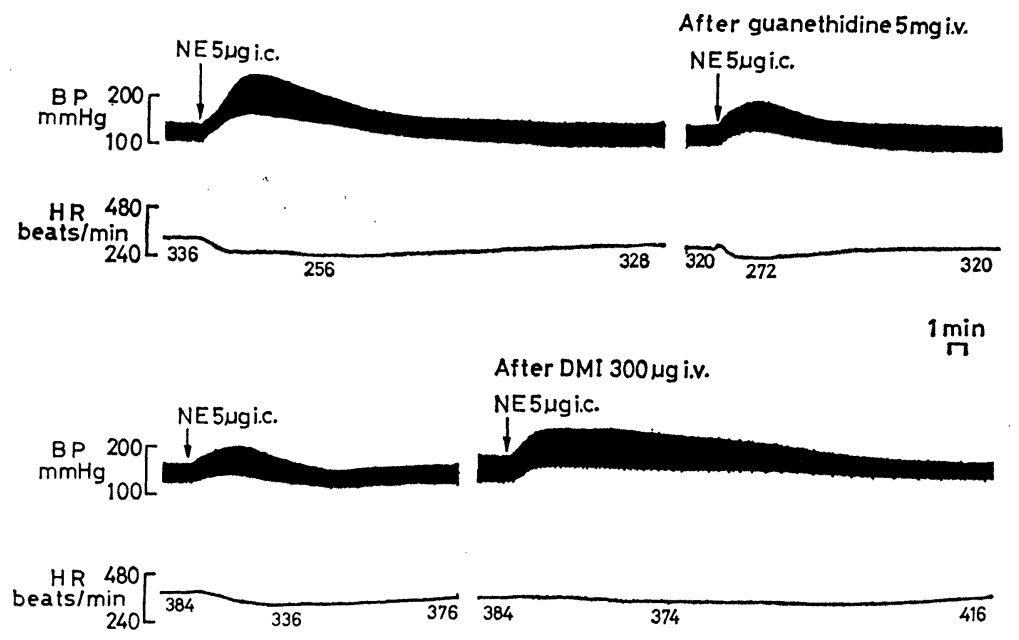

FIG. 5. The effect of the intravenous injection of guanethidine or desmethylimipramine (DMI) on the pressor response caused by the intracisternal (i.c.) injection of norepinephrine (NE) in anesthetized rats.

Upper and lower charts were obtained from two different rats (Chart speed: $5 \mathrm{~mm} / \mathrm{min}$ ). The second NE was injected $20 \mathrm{~min}$ after treatment with guanethidine or DMI.

BP: blood pressure (mm $\mathrm{Hg}), \mathrm{HR}$ : heart rate (beats/min)

as those illustrated in Fig. 1A and Fig. 1D, the following experiments were carried out and concerned these specific and typical blood pressure responses. Either typical blood pressure response, rise or fall, caused by i.c. norepinephrine $(0.5$ and $5 \mu \mathrm{g})$ was completely blocked by treatment with i.c. phentolamine (10-50 $\mu \mathrm{g}$ ), an $\alpha$-blocking agent (Fig. 2 and Fig. 3). Phentolamine (10-50 $\mu$ g i.c.) in itself showed two types of blood pressure responses, namely, a rise in blood pressure with an enlargement of pulse pressure and a remarkable tachycardia, which was sometimes accompanied by an increment of respiration rate as typically illustrated in the upper chart of Fig. 3, and a slight fall in blood pressure with a tachycardia (Fig. 3, lower chart). The response of i.c. norepinephrine was also remarkably inhibited by treatment with another $\alpha$-blocking agent, tolazoline (100-250 $\mu$ g i.c.) or chlorpromazine (10-50 $\mu \mathrm{g}$ i.c.). In addition, these two typical blood pressure responses caused by i.c. norepinephrine $(5 \mu \mathrm{g})$ changed very little even after the bilateral cervical vagal nerves had been cut (Fig. 4). Next, the effect of i.v. guanethidine $(5 \mathrm{mg})$, an adrenergic neuron blocking agent, or i.v. desmethylimipramine $(300 \mu \mathrm{g})$, a catecholamine uptake inhibitor, on the i.c. norepinephrine-induced pressor response was examined. The pressor response caused by i.c. norepinephrine $(5 \mu \mathrm{g})$ was remarkably reduced after treatment with i.v. guanethidine $(5 \mathrm{mg})$, while it was significantly potentiated after treatment with i.v. desmethylimipramine $(300 \mu \mathrm{g})$ as illustrated in Fig. 5.

\section{Epinephrine}

Blood pressure responses caused by i.c. epinephrine $(5 \mu \mathrm{g})$ were compared with those of i.c. norepinephrine $(5 \mu \mathrm{g})$. These responses caused by i.c. epinephrine were not always similar to those of i.c. norepinephrine. Epinephrine (5 $\mu \mathrm{g}$ i.c.) showed a profound rise in 

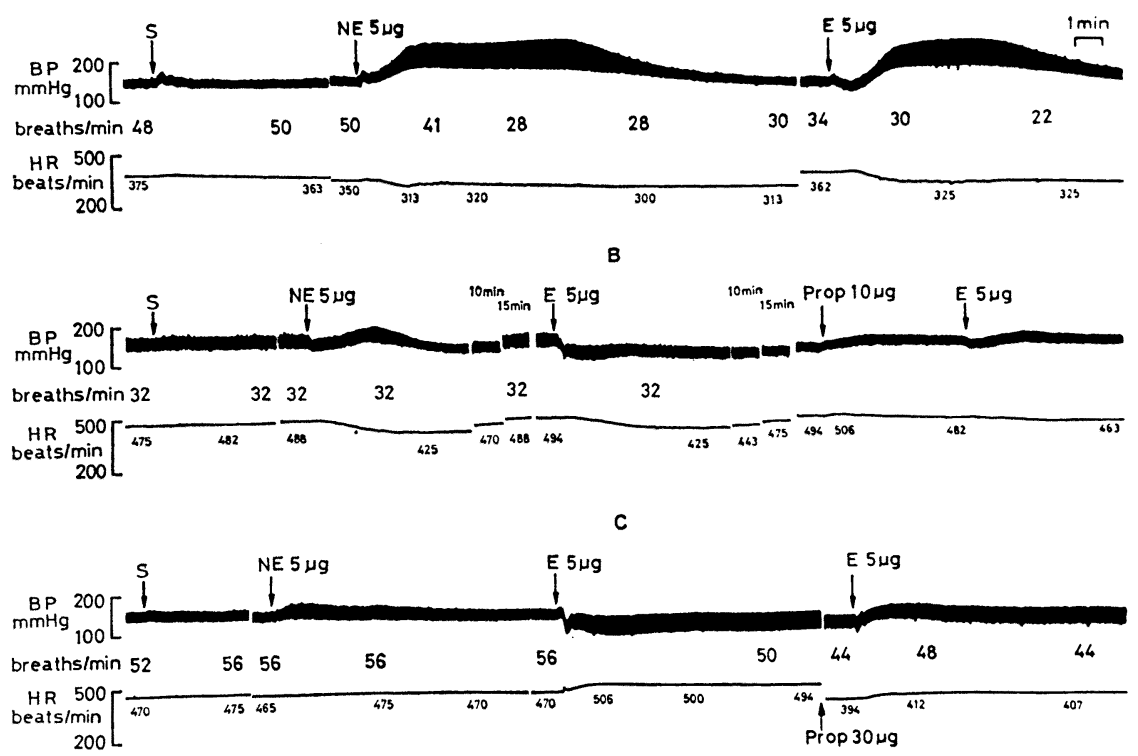

FIG. 6. Representative blood pressure responses caused by intracisternal (i.c.) injections of epinephrine (E) as compared with i.c. norepinephrine (NE) in anesthetized rats. Charts $\mathrm{A}, \mathrm{B}$ and $\mathrm{C}$ were obtained from three different rats (Chart speed: $10 \mathrm{~mm} / \mathrm{min}$ ).

BP: blood pressure ( $\mathrm{mm} \mathrm{Hg}$ ), HR: heart rate (beats/min) S: saline, Prop: propranolol (treated 10-15 min before the second $\mathrm{E}$ )

Respiration rate is indicated as breaths $/ \mathrm{min}$.

blood pressure with an enlargement of pulse pressure and a remarkable bradycardia, followed by a fall in blood pressure with a lowering of pulse pressure and a sustained bradycardia, which lasted over $30 \mathrm{~min}$ in most cases (Fig. 6A), a fall in blood pressure with an initial enlargement of pulse pressure followed by a delayed lowering of pulse pressure and a remarkable bradycardia (Fig. 6B) or a fall in blood pressure with an enlargement of pulse pressure and a considerable tachycardia (Fig. 6C). The same pattern as the first response was observed after i.c. norepinephrine. The second or third response was either only partly similar to or completely different from the patterns after i.c. norepinephrine. However, after treatment with i.c. propranolol (10-30 $\mu \mathrm{g})$, a $\beta$-blocking agent, i.c. epinephrine $(5 \mu \mathrm{g})$ showed very similar blood pressure responses to those seen with i.c. norepinephrine $(5 \mu \mathrm{g})$ as illustrated in Fig. 6B or Fig. $6 \mathrm{C}$.

\section{Isoproterenol and trimetoquinol}

L-isoproterenol (0.05-0.5 $\mu \mathrm{g}$ i.c.) usually showed a fall in blood pressure with an enlargement of pulse pressure and a considerable tachycardia, but in some cases when injections of a smaller dose of 1-isoproterenol $(0.05 \mu \mathrm{g}$ i.c.) were given, a slight rise rather than a fall in blood pressure with an enlargement of pulse pressure and a tachycardia was observed. In most cases i.c. 1-isoproterenol showed no significant change of respiration rate in anesthetized rats, different from i.c. norepinephrine, and these blood pressure responses caused by i.c. 1 -isoproterenol $(0.05-0.5 \mu \mathrm{g})$ were not significantly influenced after the bilateral 

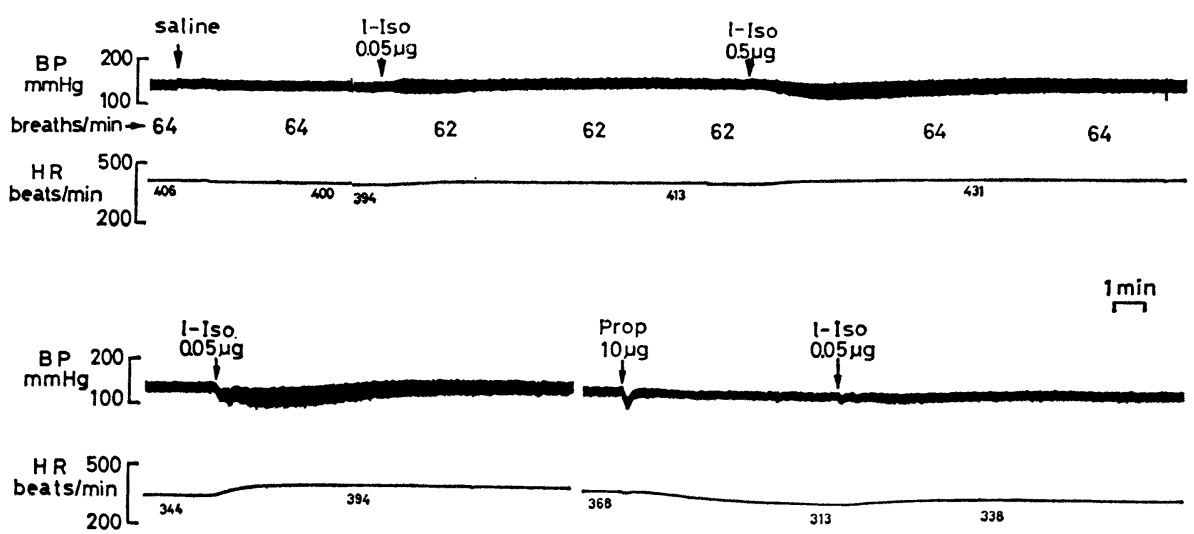

Fig. 7. Typical blood pressure responses caused by intracisternal (i.c.) injections of 1-isoproterenol (1-Iso) and the effect of i.c. propranolol (Prop) on the response caused by i.c. 1-Iso in anesthetized rats.

Upper and lower charts were obtained from two different rats (Chart speed: $10 \mathrm{~mm} / \mathrm{min}$ ).

BP: blood pressure ( $\mathrm{mm} \mathrm{Hg}$ ), HR: heart rate (beats/min)

Respiration rate is indicated as breaths/min.

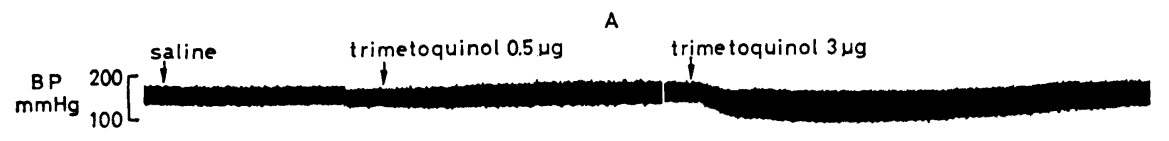

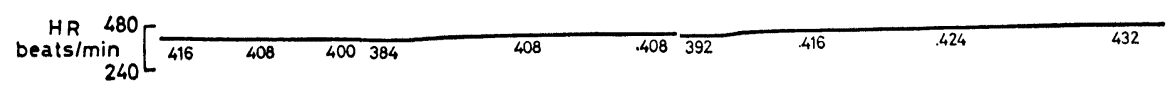
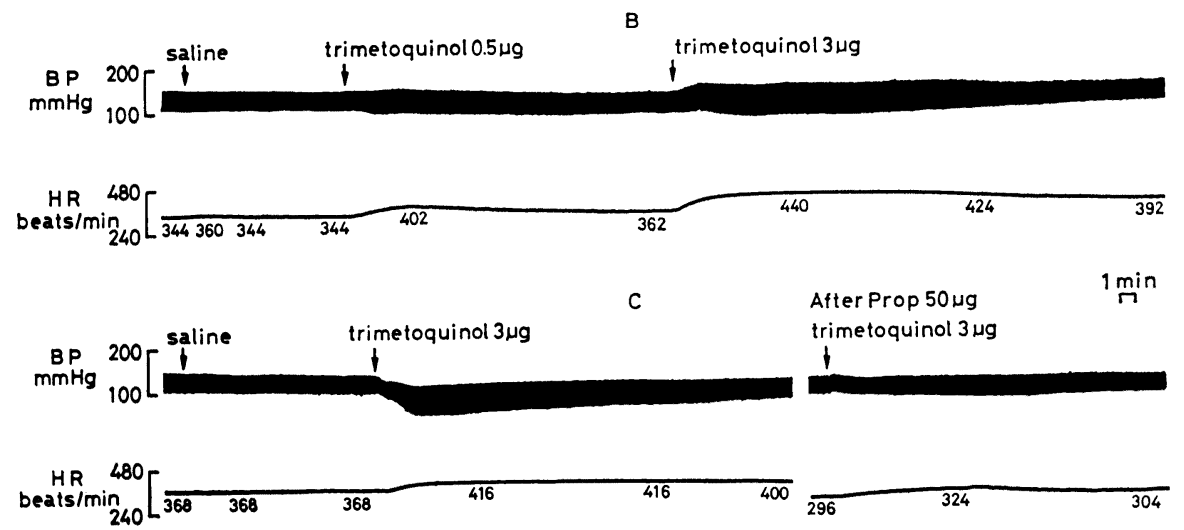

Fig. 8. Typical blood pressure responses caused by intracisternal (i.c.) injections of trimetoquinol (Chart $\mathrm{A}$ and $\mathrm{B}$ ) and the effect of i.c. propranolol (Prop) on the response caused by i.c. trimetoquinol (Chart $\mathrm{C}$ ) in anesthetized rats. Charts $\mathrm{A}$, $B$ and $C$ were obtained from three different rats (Chart speed: $5 \mathrm{~mm} / \mathrm{min}$ ). The second trimetoquinol was injected 20 min after treatment with Prop.

BP: blood pressure $(\mathrm{mm} \mathrm{Hg}), \mathrm{HR}$ : heart rate (beats $/ \mathrm{min})$ 
cervical vagal nerves had been cut. Moreover, these blood pressure responses to i.c. 1isoproterenol $(0.05-0.5 \mu \mathrm{g})$ were considerably reduced after treatment with i.c. propranolol $(10-30 \mu \mathrm{g})$. These typical responses are illustrated in Fig. 7. On the other hand, i.c. trimetoquinol $(0.5-3 \mu \mathrm{g})$, a $\beta$-sympathomimetic agent, showed two types of blood pressure responses, namely, a fall in blood pressure with an enlargement of pulse pressure and a considerable tachycardia and then a slight rise in blood pressure with an enlargement of pulse pressure and a considerable tachycardia. In particular, a small dose of i.c. trimetoquinol $(0.5 \mu \mathrm{g})$ was inclined to show a rise rather than a fall in blood pressure with an enlargement of pulse pressure and a tachycardia (Fig. 8A and $8 \mathrm{~B}$ ). This blood pressure response to i.c. trimetoquinol $(3 \mu \mathrm{g})$ was also significantly reduced after treatment with i.c. propranolol $(50 \mu \mathrm{g})$. The typical response is illustrated in Fig. 8C.

\section{Tyramine}

With tyramine (1 mg i.c.) more variable blood pressure responses were seen and in most cases they could be divided into four representative ones as illustrated in Fig. 9, namely, a mild but durable fall in blood pressure with a slight lowering of pulse pressure and a significant bradycardia (Fig. 9A), a mild fall in blood pressure with an initial enlargement of pulse pressure followed by a delayed lowering of pulse pressure and a considerable tachycardia (Fig. 9B), a remarkable durable fall in blood pressure with an initial enlargement of pulse pressure and an initial tachycardia followed by a delayed lowering of pulse pressure and a delayed bradycardia (Fig. 9C) and then a significant rise in blood pressure with an enlargement of pulse pressure and a considerable tachycardia (Fig. 9D). In the case of Fig. 6, an initial slight rise in blood pressure with an enlargement of pulse pressure and a tachycardia was sometimes observed after i.c. tyramine $(1 \mathrm{mg})$. These responses caused by i.c. tyramine $(1 \mathrm{mg})$ were more variable but of relatively longer duration, and in par-

A
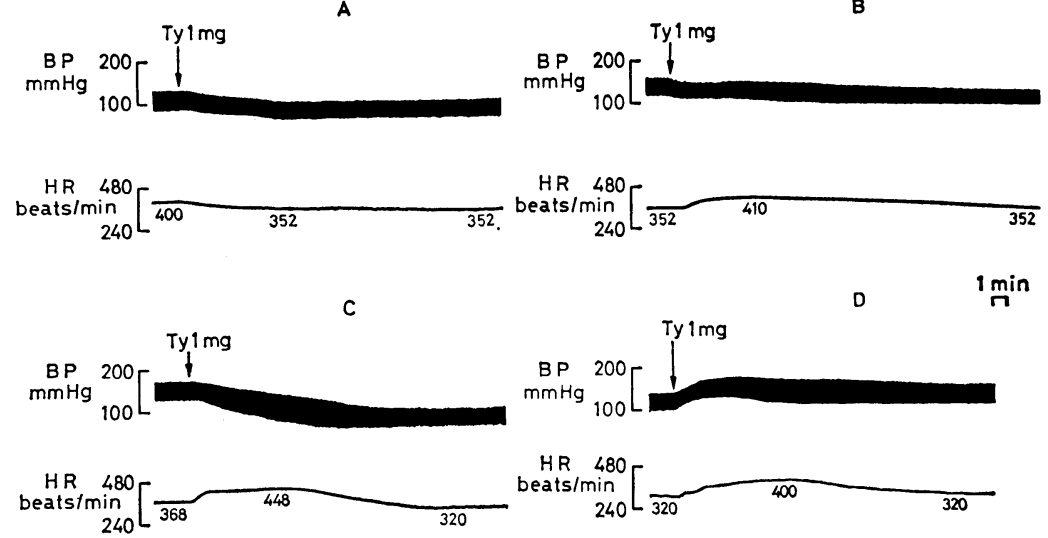

FIG. 9. Representative blood pressure responses caused by intracisternal (i.c.) injections of tyramine (Ty) in anesthetized rats.

Each and all charts were obtained from four different rats (Chart speed: $5 \mathrm{~mm} /$ $\min )$.

BP: blood pressure ( $\mathrm{mm} \mathrm{Hg}$ ), HR: heart rate (beats $/ \mathrm{min}$ ) 
ticular, the maximum depressor response lasted over one hour. Comparing these blood pressure responses of i.v. and i.c. tyramine $(1 \mathrm{mg})$ with those of i.v. and i.c. norepinephrine (5 $\mu \mathrm{g})$, tyramine $(1 \mathrm{mg})$ showed a larger but similar pressor response to that of norepinephrine $(5 \mu \mathrm{g})$ in the case of the i.v. administration, while in the case of the i.c. administration, it was characteristic that tyramine $(1 \mathrm{mg})$ was inclined to show a more durable fall in blood pressure and rarely caused a smaller pressor response than did norepinephrine $(5 \mu \mathrm{g})$ (Fig.
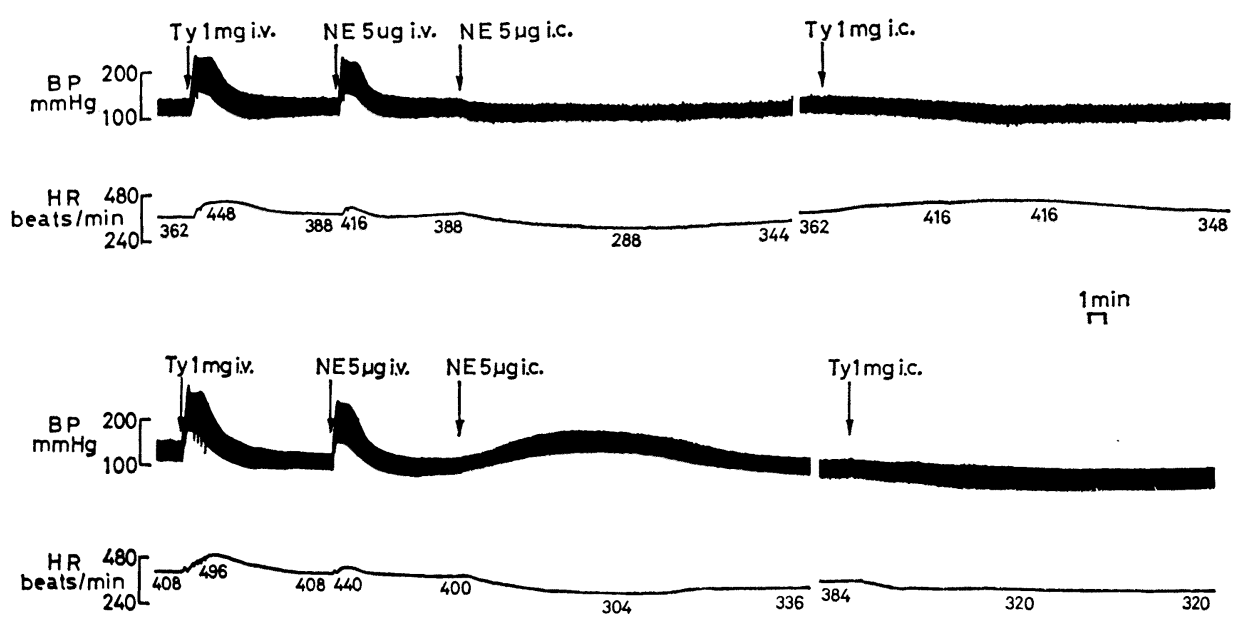

FIG. 10. Typical blood pressure responses caused by intravenous (i.v.) and intracisternal (i.c.) injections of tyramine (Ty) as compared with responses after i.v. and i.c. norepinephrine (NE) in anesthetized rats.

Upper and lower charts were obtained from two different rats (Chart speed: $5 \mathrm{~mm} / \mathrm{min}$ ).

BP: blood pressure ( $\mathrm{mm} \mathrm{Hg}$ ), HR: heart rate (beats/min)

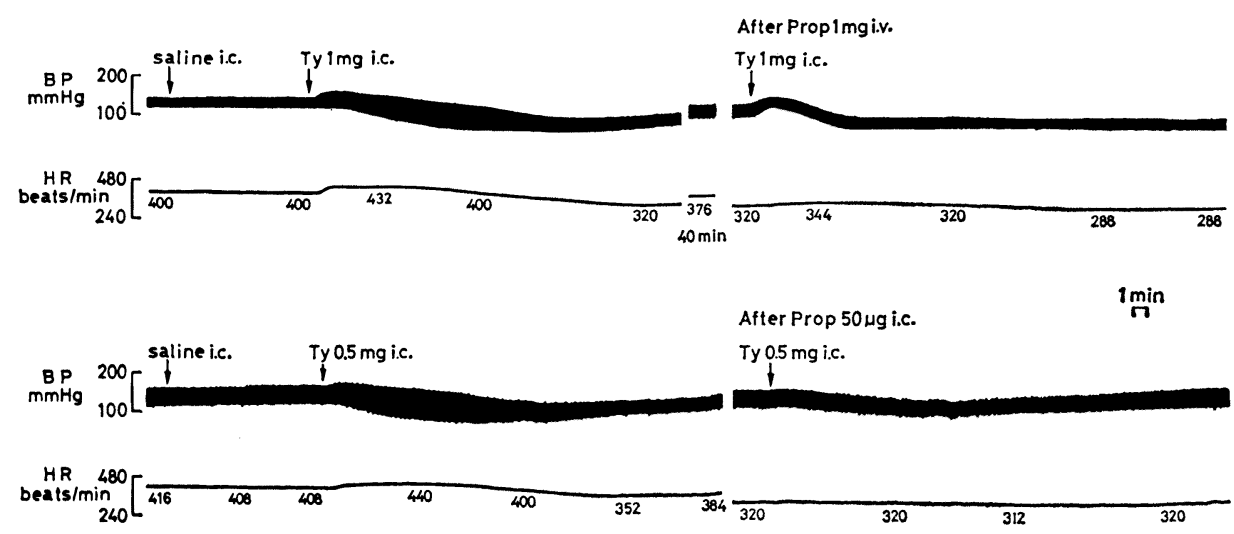

FIG. 11. Effects of intravenous (i.v.) and intracisternal (i.c.) injections of propranolol (Prop) on the typical response caused by i.c. tyramine (Ty).

Upper and lower charts were obtained from two different rats (Chart speed: $5 \mathrm{~mm} / \mathrm{min}$ ). The second Ty was injected $20 \mathrm{~min}$ after treatment with i.v. or i.c. Prop.

BP: blood pressure $(\mathrm{mm} \mathrm{Hg}), \mathrm{HR}$ : heart rate (beats/min) 
10). The blood pressure response caused by i.c. tyramine $(0.5-1 \mathrm{mg})$ was partially blocked by treatment with i.c. phentolamine $(50-100 \mu \mathrm{g})$ or i.c. propranolol $(50-100 \mu \mathrm{g})$. The typical response after treatment with i.v. and i.c. propranolol is illustrated in Fig. 11. Thus, it was observed that one aspect of the blood pressure response caused by i.c. tyramine $(0.5-1 \mathrm{mg})$, that is the enlargement of pulse pressure and the tachycardia, was effectively blocked after treatment with propranolol (50 $\mu$ g i.c. or $1 \mathrm{mg}$ i.v.) but the delayed durable fall in blood pressure with a delayed bradycardia caused by i.c. tyramine $(0.5$ or $1 \mathrm{mg})$ remained unchanged (Fig. 11).

\section{DISCUSSION}

Firstly, it is characteristic that the pressor response with no significant change of heart rate or a bradycardia besides the depressor response with a bradycardia occurring regularly is observed with i.c. norepinephrine in anesthetized rats as compared with other observations after the injection of norepinephrine into the cerebral lateral ventricle in anesthetized dogs $(1,2)$, cats (3-6) and rabbits (7). It can be reasonably ascertained that the depressor response with a bradycardia which occurred regularly with i.c. norepinephrine originated in the central mechanism and was due to a $\alpha$-sympathomimetic action of norepinephrine, since 1) this response to i.c. norepinephrine is quite different from that of i.v. norepinephrine, 2) this response to i.c. norepinephrine is completely blocked by a small dose of i.c. phentolamine or another $\alpha$-blocking agent (the same dose of i.v. phentolamine or another $\alpha$-blocking agent has no $\alpha$-blocking effect) etc.. Moreover, it is considered that the characteristic pressor response to i.c. norepinephrine in anesthetized rats is not due to a leakage of norepinephrine from the cerebrospinal fluid into the systemic circulation but rather originates in the central mechanism and due to a $\alpha$-sympathomimetic action of norepinephrine, since 1) the pressor response to i.c. norepinephrine has a relatively longer duration than that of i.v. norepinephrine, 2) the pressor response to i.c. norepinephrine is completely blocked by a small dose of i.c. phentolamine or another $\alpha$-blocking agent (the same dose of i.v. phentolamine or the other shows no $\alpha$-blocking effect), 3) the pressure response to i.c. norepinephrine is significantly reduced by i.v. guanethidine, 4) this phenomenon to i.c. norepinephrine is in agreement with the other observation after i.vt. norepinephrine in reserpinized and anesthetized

cats (4). Perhaps, the pressor response to the central administration of norepinephrine may be usually masked under the depressor one in other species of anesthetized animals. Secondly, it has been reported that i.vt. isoproterenol usually causes the depressor response with a tachycardia in anesthetized dogs $(1,2)$, cats (6) and rabbits (7). However, Day and Roach (9) have recently reported that a tachycardia regularly occurs but the effects on blood pressure are more variable in response to i.vt. isoproterenol using conscious cats, and moreover, in conscious rabbits and rats, a small rise in blood pressure with a tachycardia is observed. In contrast, Dollery et al (10), using conscious rabbits, have reported a depressor response to i.vt. isoproterenol. Thus, the blood pressure responses to i.vt. isoproterenol are not always consistent among different species or states of anesthesia. Our results obtained with i.c. 1-isoproterenol or trimetoquinol in anesthetized rats indicate that the central 
$\beta$-sympathomimetic effects cause both pressor and depressor responses, and a tachycardia regularly occurs. In particular, i.c. trimetoquinol has a tendency to cause the pressor response with a tachycardia. It has already been reported that the cardiovascular effect to i.v. trimetoquinol is one fifth as potent as that of i.v. isoproterenol in anethetized rats (11). Thirdly, i.c. epinephrine shows both central $\alpha$ - and $\beta$-sympathomimetic effects on blood pressure in anesthetized rats as does i.v. epinephrine, and moreover, these effects to i.c. epinephrine can be characteristically separated into the $\alpha$ - or $\beta$-dominant one. It may be considered that the concentration gradient of epinephrine occurs on both zones of the vasomotor center presumably due to the different sites of the injections of epinephrine, so that i.c. epinephrine exerts the selective effect on either $\alpha$ - or $\beta$-sensitive zone. However, these phenomena caused by i.c. epinephrine in anesthetized rats may not necessarily be observed in other species of anesthetized animals. Actually it has been reported that i.vt. epinephrine usually shows the depressor response with a bradycardia due to the central $\alpha$-sympathomimetic action of epinephrine in anesthetized rabbits (7). Fourthly, it has been reported that in anesthetized cats, i.vt. tyramine exerts the pressor response with a tachycardia through a release of catecholamines on the vasomotor center (12). In anesthetized rats, i.c. tyramine shows more variable blood pressure responses such as those observed by i.c. norepinephrine, epinephrine and isoproterenol, and moreover, these blood pressure responses to i.c. tyramine are partially blocked by treatment with an $\alpha$ - or $\beta$-blocking agent injected i.c., and it has been recently reported that there exist epinephrine related neurons as well as norepinephrine ones in the rat brain $(13,14)$, so it is considered that i.c. tyramine exerts central $\alpha$ - and $\beta$-sympathomimetic effects through a release of norepinephrine and epinephrine on the vasomotor center of the pons and medulla in anesthetized rats. Finally, i.c. propranolol in itself usually causes a slight depressor response with a remarkable bradycardia in anesthetized rats (the same dose of i.v. propranolol shows no cardiovascular effect), in agreement with other observations after the central administration of propranolol in anesthetized dogs $(15,16)$ and cats $(17)$, and also in conscious cats $(9,18)$ and rabbits $(10)$. In contrast to the effect of i.c. propranolol, i.c. phentolamine, not always but in most cases causes a pressor response with a significant tachycardia occurring regularly in agreement with the other observation (19). It is possible that either $\alpha$ - or $\beta$-sensitive zone on the vasomotor center is blocked by i.c. the $\alpha$ - or $\beta$-blocking agent, so that the $\alpha$-or the $\beta$-dominant state occurs on the vasomotor center and it results in the depressor response with a bradycardia or the pressor one with a tachycardia.

From the above findings, it is suggested that there may exist both $\alpha$ - and $\beta$-sensitive adrenergic zones, which centrally control the blood pressure, these zones may be on the vasomotor center of the pons and medulla in rats, and both norepinephrine and epinephrine may play a physiological role as the chemical transmitters in that mechanism, eliciting the central $\alpha$ - and $\beta$-sympathomimetic effect, respectively. In particular, it is considered that these transmitters exert their effects on blood pressure through centrally mediated stimuatory and inhibitory cardiac actions. Further studies are underway to confirm our hypothesis. 


\section{REFERENCES}

1) McCubbin, J.W., Kaneko, Y. And Page, I.H.: Circulation Res. 8, 849 (1960)

2) Bhargava, K.P., Mishra, N. And Tangri, K.K.: Brit. J. Pharmacol. 45, 596 (1972)

3) Nashold, B.S., Mannarino, E. ANd Wunderlich, M.: Nature 193, 1297 (1962)

4) Share, N.N. and Melville, K.I.: J. Pharmacol. exp. Ther. 141, 15 (1963)

5) Smookler, H.H., Severs, W.B., Kinnard, W.J. and Buckley, J.P.: J. Pharmacol. exp. Ther. 153, 485 (1966)

6) Gagnon, D.J. AND Melville, K.I.: Int. J. Neuropharmacol. 6, 245 (1967)

7) Toda, N., Matsuda, Y. ANd Shimamoto, K.: Int. J. Neuropharmacol. 8, 451 (1969)

8) Share, N.N.: Archs int. Pharmacodyn. Thér. 202, 362 (1973)

9) Day, M.D. ANd Roach, A.G.: Brit. J. Pharmacol. 51, 325 (1974)

10) Dollery, C.T., Lewis, P.J., Myers, M.G. ANd Reid, J.L.: Brit. J. Pharmacol. 48, 343 (1973)

11) Sato, M., Yamaguchi, I. AND KiYomoto, A.: Japan. J. Pharmacol. 17, 153 (1967)

12) Share, N.N. ANd Melville, K.I.: Archs int Pharmacodyn. Thér 153, 267 (1965)

13) Hökfelt, T., Fuxe, K. Goldstein, M. and Johansson, O.: Acta plysiol. scand. 89, 286 (1973)

14) Hökfelt, T., Fuxe, K., Goldstein, M. and Johansson, O.: Brain Res. 66, 235 (1974)

15) Srivastava, R.K., Kulshvestha, V.K., Singh, N. and Bhargava, K.P.: Europ. J. Pharmacol. 21, 222 (1973)

16) Caster, J.K., Mitchell, H.W. and Poyser, R.H.: Brit. J. Pharmacol. 51, 146 (1974)

17) Kelliher, G.J. ANd Buckley, J.P.: J. Pharm. Sci. 59, 1276 (1970)

18) Day, M.D. ANd Roach, A.G.: Clin. exp. Pharmacol. Physiol. 1, 333 (1974)

19) Hilliard, C.C., Bagwell, E.E. ANd Daniell, H.B.: Europ. J. Pharmacol. 18, 338 (1972) 